\title{
Looking over our shoulders: critical thinking and ontological insecurity in higher education
}

\author{
Anna Jones* \\ University of Melbourne, Australia
}

This paper examines the changing landscape of higher education from the perspective of teaching academics. Critical thinking has been seen as one of the central facets of the academic identity and so this paper uses the notion of critical thinking as a lens through which to explore this changing identity. It argues that the professional identity of the academic is in a state of flux, which has caused uncertainty regarding the academic role, its freedoms and responsibilities. The particular focus here is on teaching and the changes occurring in this arena. The paper reports the findings of a qualitative study based on in-depth interviews with academic staff across five disciplines from two Australian universities. In the modern university, the pressures of accountability to a range of stakeholders, both internal and external, are changing the face of university teaching.

\section{Introduction}

Higher education is changing and this has created uncertainty regarding the academic identity. This paper focuses on one site of this uncertainty, the notion of critical thinking. The central aim of this paper is to point to the paradox that while the capacity for critical thought is central to the academic identity, along with changes in the role of the academic have come changes in the centrality of critique. This paper examines the complexities of teaching in the context of a higher education environment in which critique has become commodified. It uses the notion of critical thinking as a pivot around which the changing nature of the academic role in higher education is discussed. The starting point for this paper was a study which investigated the ways in which generic attributes (including critical thinking) were constructed and taught by academics in a range of disciplines. However, my discussions with academic staff revealed unexpected layers of meaning. In discussing

\footnotetext{
*Teaching and Learning Unit, Faculty of Economics and Commerce, University of Melbourne, Parkville, Victoria, 3010 Australia. Email: annalj@unimelb.edu.au
} 
the teaching of critical thinking, staff talked of the difficulties not only of teaching critical thinking but of thinking critically about their own teaching, or more specifically, voicing concerns about their teaching in public places rather than backstage or offstage (Goffman, 1956) in the privacy of offices and staff clubs (or in de-identified interviews with researchers). Academic staff were concerned about the changes that were taking place in higher education but were increasingly dubious about how to voice these concerns. An examination of this then revealed further layers of ambivalence about the role of the academic. This paper explores these layers, using the notion of critical thinking as a focal point. However, what it reveals is a deep uncertainty about the place of higher education.

The change in the positioning of critical thinking has occurred against a backdrop of fundamental changes in universities. A number of writers (Gale, 2000; McWilliam, 2002; Ball, 2003; Barnett, 2003; Morley, 2003) have commented on the extent to which academic staff are subject to a culture of audit and accountability. Decreasing per capita funding in UK, Australian and New Zealand universities has accompanied increased accountability (McWilliam, 2002). Higher education has become a field characterised by hierarchical observation: governments observe institutions, which observe faculties and departments, which observe academics (Gale, 2000) and so everything needs to be evaluated, justified and to be accountable (Morley, 2003). Yet within all this accountability, where is the space for critique? Academic staff are subject to scrutiny across a range of levels (research, performance appraisal, teaching evaluations, grant applications, applications for promotion or confirmation) and as a consequence have become more reluctant to critique the processes which are evaluating and monitoring them. As Barnett (1994, p. II5) points out, internal critique has to be kept within limits and 'has to remain relatively mute in the context of the new managerialism ... critique had better know its limits'.

Critical thinking can be defined in a number of ways but is considered to be one of the central functions of the university. It is considered to be central to what academic staff do both in teaching and research and central to the ways of thinking in which students are being apprenticed. In all the disciplines considered in this study, critical thinking was central to disciplinary epistemology, to the research process and to teaching (Jones, 2006, 2007). There is considerable interest in the nature of critical thinking (Ennis, 1987; Kurfiss, 1988; Facione, 1990; McPeck, 1990; Ramsden, 1992; Barnett, 1997; van der Wal, 1999; Fallows \& Steven, 2000; Australian Council for Educational Research, 200I). However, critical thinking is in the process of being packaged, shrinkwrapped and is in danger of losing its power. It is used to promote the value of a university education yet at the same time the real power and value of critical thinking to interrogate is declining. This paper reflects on the ways in which the culture of quality, audit and control, the 'new managerialism' (Barnett, 1994; Morley, 2003), is reducing academics' ability to question and critique. It considers this only from the perspective of teaching and does not seek to comment directly upon critical thinking within research. It argues that the reasons critical thinking is endangered are twofold: firstly it is not always valued by management in the department or institution as a whole, and secondly teaching has become more highly structured and risk averse. This paper does not argue that critical thinking is not taught, nor does it suggest that it does not occur in research, teaching or in the institutional setting, but rather that for some academics, active and public critique is an increasingly difficult proposition. 
Much has been written on the nature of critical thinking and in the majority of this literature it is defined as the cognitive skill of problem solving and logic (McPeck, 198I; Ennis, 1987; Kurfiss, 1988; Siegel, 1988; Paul, 1989; Halpern, 1996; Facione, 1996-97). As a problem solving skill, critical thinking requires the operational system of the particular type of problem, for example mathematical, economic or clinical. It often utilises logico-deductive reasoning; however, this is not the only form of problem solving. Critical thinking is also understood as argument analysis and as such requires understanding of informal logic, definitions, evidence, assumptions, conclusions and implications as well as the knowledge and theoretical basis of the discipline in question. However, Barnett (1997) takes the definition of critical thinking further, arguing that it can also be understood as metacriticism or 'critique in action'. This form of critical thinking is a transformative process and is the ability to engage in critical self-reflection and to critique a discipline or social process from outside its fundamental assumptions. In Pennycook's (200I) terms, it is a critique of social relations which encompasses notions of power and structure and ideas about change for the betterment of society. This can also be described in Habermas' terms as the 'emancipatory' form of critical reasoning as opposed to 'instrumental' reasoning which is much more pragmatic (Habermas, 197I). The ways in which critical thinking is constructed are influenced by a number of factors, including the disciplinary culture (Jones, 2006). Hence, critical thinking is a very complex notion and operates at a number of levels and this paper acknowledges that the term 'critical thinking' covers an array of ideas and practices, from technical problem solving to a critical examination of a discipline to a much broader critique of society. In this paper, the term 'critical thinking' is used to cover the breadth of understandings and to cover the thinking of both staff and students. However, it is in part the slipperiness of the notion of critical thinking which means it can be redefined or appropriated in many ways.

\section{The study}

This paper arose out of a larger study which examined the relationship between disciplinary epistemology and generic skills in higher education. The interviews upon which this paper is based did not specifically seek to discuss attitudes towards the academic role and identity, nor did they seek to identify any change in the nature of critical thinking. The interviews examined the epistemology of the participants' disciplines, their perceptions of generic skills and how these were taught and assessed. However, in the process of discussing these matters with participants, the issue of critical thinking and more fundamental questions about the changing role of the academic surfaced, unbidden, with a regularity that was difficult to put aside. In discussing the nature of generic skills in their discipline, academic staff referred to the changing nature of teaching, their increased accountability and their changing roles within the academy. This is not a large-scale study and the findings are limited to two universities which are quite similar in profile. However, the questions raised by the academics in this study resonate with findings in the literature.

This paper is based on in-depth interviews with academic staff in two large, researchintensive Australian universities. The study focused on five disciplines-history, physics, economics, medicine and law. Academic staff in each discipline were selected to allow for 
a broad range of specialisations or areas of interest. Further, in selecting participants, the aim was also to have a range of age, experience and position level. A total of seven participants were interviewed in law and nine in medicine, six in history, eight in economics and seven in physics. In medicine, two of the participants were not medical practitioners but were key to medical education in their respective schools. Each interview was between 50 and 90 minutes in length. Interviews were semi-structured to allow for exploration of individual thinking. Interviews were audio recorded and transcribed in full. Analysis was emergent and was carried out with the use of QSR NVivo software. This coding involved re-reading and validation through cross-checking across all transcripts. From this coding, themes or patterns were identified and refined. Hypothetical relationships identified in the initial coding were confirmed, modified or rejected on the basis of this process. In addition to the formal interviews, the researcher had a number of informal conversations with a range of people from each of the disciplines to gain some background into the culture of the disciplines and into the educational issues that were pertinent to each area.

\section{The view from the lectern}

This paper argues that there is a growing ambivalence regarding what constitutes the identity of the academic and that this can be reflected through the ways in which notions of critical thinking are articulated. The participants in this study argued that critical thinking in a variety of forms is key to their role as academics. The forms that critical thinking took for these participants included the ability to tackle the central problems of their discipline, constructive critique of their own work and the work of peers in their role as researchers, examination of the inner workings of a discipline, a broader examination of the role of their discipline or profession in society and the ability to critique the workings of society. In addition, central to the teaching role of most academics is the engendering of critical thinking (again in a range of forms) in students. While the practice of teaching critical thinking to students is not the central focus of this paper, because all of the participants were teaching as well as research staff, their interest was as much in their role as teachers of critical thinking as in being critical thinkers themselves and these two roles were conceived of as being intertwined. Moreover, it was through a discussion of teaching critical thinking that participants reflected on their own place within higher education. Participants argued that they no longer felt a sense of certainty regarding their expertise as teachers and what constituted good teaching, and as part of this no longer felt a sense of certainty regarding the place of criticality.

There is uncertainty regarding whether notions of good teaching encompass teaching disciplinary knowledge or teaching skills that are detached from disciplinary content, uncertainty about whether to prepare students to be excellent historians, physicists or economists or prepare them for some quite different future (and a future about which a historian, physicist or economist may have little expertise). There are concerns about whether a teacher's primary aim is to entertain or to challenge, whether learning should be pleasant or uncomfortable, whether teachers aim for high teaching evaluations or concentrate on other forms of evaluations. And this is just the realm of teaching. Alongside this academics must, of course, consider whether their primary focus is their teaching or their 
research and whether their primary allegiance is to their disciplinary community, department, university or students.

\section{An archaeology of uncertainty}

The layers of thought regarding the role of the academic in a changing landscape can be peeled back to reveal a complex set of understandings. The first layer is the practice of teaching critical thinking. Much of this has been discussed elsewhere (Jones, 2006) and concerns different constructions of critical thinking. However, the issue of critical thinking is described by the participants as highly complex and problematic. The academic staff interviewed in this study identified a number of reasons behind their concerns regarding critical thinking. These include a certain resistance to critical thinking on the part of some students. The notion that students were resistant to critical thinking is recurrent in the interviews, although it must be emphasised that academic staff did not suggest that this applied to all students, nor did they suggest that this was something new.

I see the function of teaching history as being to try and teach about the past and also critical thinking about it. And my students ... their resistance to it is extraordinary. Just incredible... And then I give up, I decide I can't teach it any more. It is too hard. I do find it very hard to make students engage in a critical kind of way with the fact that the history they are reading is not just about accumulated information but is actually about an argument. (History)

There is a small proportion, probably highly represented in that 10\% who don't apply, aren't interested, didn't enjoy that sort of stuff [challenging assumptions or received wisdom] for whom that is a very threatening, challenging thing. For them science and education is 'tell me what I need to know, what I need to regurgitate, tell me what the facts are, what the answers are and I will spit that back out to you during the exam'. That is knowledge for them. (Medicine)

I get the feeling that there are large numbers for whom talking would be a completely foreign idea. Not just those in the bottom fifty percent. They would not want to talk about the subject of the lecture. They might want to talk about whether the lecturer was crappy but they would not sit over a cup of coffee and argue about economics ... It is so much go with the flow. (Economics)

They are not happy [about the contradictions inherent in law] because they don't think rules should contradict or judges should contradict each other ... the law should be clear ... They don't like that, they want clarity. They want a set of bullet points, they want a flow chart. (Law)

What is significant here is not that students are resistant to ambiguity, as this may have always been the case and may be a consequence of age, lack of confidence or a consequence of a more instrumentalist approach to learning resulting from increased student employment and reduced time spent on campus (Mclnnis, 200I). What is important in the context of this paper is that academics feel that they have less control over the content and flavour of their curriculum as they are under pressure to please students in ways that may not always be educationally sound. So if some students are resistant to critical thinking (as they may always have been) it is now more risky to challenge and cajole them into thinking critically because although it may ultimately be valued, at the time it can be uncomfortable. It 
is at this point that the second layer of thinking is uncovered. This second layer is an uncertainty about what constitutes good teaching. Academic staff are not concerned simply because students may be resistant to thinking critically but because pushing or encouraging students into doing something they are resistant to is now more problematic because the nature of the teacher/student relationship has changed. Students now demand value for money and have increasing influence over the content of the curriculum as a result of student evaluations and so if critical thinking is not part of this notion of 'value', then there is some anxiety on the part of teaching staff regarding including this in their teaching.

Furthermore, some academics argued that students had a set of expectations about university and it was becoming increasingly difficult to go against these expectations.

My impression is that if you push students to do this kind of stuff you are going to get bad evaluations. (Economics)

If we are going to have evaluations of teachers that basically forces the dumbing down of subjects, what it does is it forces the academics to give students stuff all the time because that is one of the ways that is seen as keeping your evaluations up. People feed stuff to the students all the time and what it does is it makes students less willing to work themselves. It introduces dependency. (Economics)

I think that the university has this emphasis, almost an expectation from management that every course should be exciting and interesting and if you think about some of the foundation courses in econometrics or real analysis or maths, unless you are really weird, you just ain't going to enjoy it. You are not going to enjoy it but it is useful. I do think the university idea is that every course should be exciting and I think that is a really bad idea. It sets up the wrong expectation whereas I think we should set up expectations that students should achieve certain things and that at some stages the material will be really interesting and at other stages it won't be. (Economics)

The whole business of fees has made students think 'are you getting value for money?' But define value. Are we going to train them? (Physics)

Participants discussed their perception that there is increasing pressure to provide students with more highly structured material and to require less autonomy and initiative from students. Participants also described their doubts about the use of highly structured PowerPoint slides and the provision of very detailed lecture notes and the ways in which this encouraged dependency.

The issues raised here move from specific concerns about the teaching of critical thinking to deeper concerns about what good teaching entails, the role of the teacher, managing or responding to the expectations of students and the pressure of responding to ongoing evaluation of teaching performance. Many of the issues raised by participants in the present study are outlined by Morley (2003), who writes of the reconstruction of students as consumers. She describes the relationship between teachers and students as having lost its innocence. One of the participants in her study remarked that it is no longer 'an interaction between themselves as teachers and their students. There will always be external third parties lurking in the background' (p. 74). Teaching is seen as an increasingly risky exercise as students exercise more power. There is an increasing expectation that academics will be readily available to students, and that students need to be pacified. Yet larger classes mean that the time actually spent individually with students has decreased. 
Reliance on student evaluation has assumed that 'the voice of the consumer is stable, pure, concrete and is the authentic indicator of democracy' (p. 137). Morley suggests that academic staff are increasingly being subordinated to unaccountable and anonymised student criticism and she questions whether the customer is the ultimate authority since 'like surgery it is difficult for purchasers to evaluate at the point of delivery' (p. I38). Thus the role of the academic as challenging, questioning and even discomforting is undermined by what Morley refers to as the need for the 'feel good factor'. In terms of teaching, Barnett (1994) suggests that although critical thinking is on the agenda, courses are becoming increasingly tightly managed with clear outcomes and structures and so risk is minimised, learning is predictable and 'critical thinking is squeezed out' ( $p .1 / 8)$.

A further but related concern voiced by participants in the present study is that educational policy has been formulated by those who are not involved with the day-to-day pressures of teaching, people for whom teaching is not essential to the progression of their career such as those who work in government departments and university management. In many cases, those who make decisions are making them on grounds other than educational ones, for example economic efficiency.

At the moment you just feel like you are living in this surreal world where people who have never taught, who have never laboured with the practice of teaching make decisions about how teaching is accomplished and then make other kinds of decisions about how the world in which that teaching takes place is shaped in terms of funding ... I would really like to get some DEST $^{1}$ people and some people from our chancellory just to come and work for a couple of weeks and see what it feels like. (History)

So where is the imposition [in this case of teaching generic skills] coming from? Well, in our case it sort of comes down from teaching committees, undergraduate committees, quality assurance, whatever it is, that whole bureaucracy. (Economics)

I spent hours on the subject outline, giving information on plagiarism, on the retention of exams. A six page handout, web pages and so on. All of that is part of the machinery which intrudes into the core business which we ought to be on about and sort of governs the whole thing. You are increasingly looking over your shoulder. Policies here, policies there. You become awfully self conscious about what you are doing, and circumspect. (Economics)

There is a clear sense amongst some of the participants in this study that they have less autonomy in their teaching and that the erosion of their autonomy is a result of managerial control both internal and external. It is here that the third layer of understanding can be seen. Not only is the nature of teaching changing but the authority of the academic to critique the social context of that change is shifting. Teaching has always been a risky undertaking because it is a subtle combination of performance and retreat, encouragement and assessment, support and challenge. Good teaching also involves a process of risk taking, trial and error. However, increasingly this fundamentally risky endeavour is taking place in an increasingly risk-averse environment.

Teaching is a particularly complex area since it is both a private and public act, public in that classes are open, yet private in that one has a particular relationship with and responsibility to one's students. As Shulman (1993, p. 6) remarks, 'we close the classroom door and experience pedagogical solitude'. For most academics, preparation of material and teaching of classes is a private act, even if it is done in consultation with colleagues. The 
way material is presented, the style of teaching and the relationships with students are largely private. However, since teaching has become part of academic accountability, it is judged in often very public ways, with teaching evaluations sometimes used to determine continuing employment or promotion. Further, teaching by its very nature is a public act. It is a performance, often in front of very large groups of students (some of the staff interviewed for this study taught classes of up to 500 students at a time, often several times a week). Questions of performance come into teachers' thinking about their teachingwhat sort of stories or jokes to tell, how to judge whether the material is delivered too quickly or too slowly, the manner and personal style of the person giving the class.

So teaching becomes a public act upon which the teacher will be judged, not only by his or her students. Teaching becomes a site of evaluation and management. Ball (2003, p. 2I6) describes this phenomenon in terms of performativity, a notion derived from Lyotard. He defines performativity as a:

... culture and mode of regulation that employs judgements, comparisons and displays as a means of incentive, control, attrition and change-based on rewards and sanctions ... The performances (of individual subjects or organizations) serve as measures of productivity or output or displays of 'quality' or 'moments' of promotion or inspection.

Thus performativity becomes a culture of control and Ball sees this as a battle over the teacher's soul. Increasingly teaching is influenced by surveillance and monitoring systems which create uncertainty and make one "continually accountable and constantly recorded' (Ball, 2003, p. 216). Ball points out that performativity is not just about the individual but about the organisation. We are expected to care about our team, our institution. Institutions are expected to compete with and differentiate themselves from each other and so our performance is about the 'construction of convincing institutional spectacles' (p. 224) whether they be university rankings or awards. As Barnett (1999) suggests, academics are expected to take on a public persona and to identify with the larger managerial and strategic project and mission of the university. Ball (2003) argues that performativity creates ontological insecurity in which academics ask: Are we doing enough? Are we doing the right thing? How will we measure up?

As Morley (2003) points out, performativity is linked to discourse and the ways in which the cultural hegemony of dominant groups in society is secured and contested. She suggests that the quality discourse is 'engulfing professional consciousness and dominating organisational priorities' (p. 72). New managerialism has demanded that all academics display characteristics of the hegemonic rather than counter-hegemonic intellectuals. In this climate, any analysis of power and power relations has to be suspended. Thus the power of academics to provide any serious critique of the institutions and systems in which they work is threatened. Discourse provides frameworks within which thought is structured. However, the nature of a discourse is that it often restricts and discourages a fundamental examination of the framework itself. Notions of academic freedom and the importance of the role of universities in providing a critique of society (including the academy itself) are no longer central to the new discourse of the university.

For many of the academics interviewed in the present study, the changes in higher education have resulted in a change in their identity as academics. The increasing role of 
students in providing feedback on the performance of teaching staff has altered the position of the teacher and caused some of the participants to question their beliefs about teaching. Some suggested that they taught in ways that were strategic rather than in ways that matched their educational philosophies. Yet another factor in the changing identity of the academics in this study is the growing interest in pedagogy in higher education and the rise of academic developers who are experts in teaching in the higher education context. Thus the academic is no longer an expert regarding his or her own teaching but may refer (or in some cases defer) to a teaching expert. For some academics in this study, the teaching support that came from academic development (or what one participant referred to as 'the educationalists') was suspect as there was a fear that they had been co-opted by management and had a surveillance role as 'teaching police'. Land (2003), outlining approaches to academic development, describes the managerial and the political strategist as two key orientations to academic development. The former is firmly aligned with the institutional mission and the latter operates according to the shifting power relations within the organisation. These are not the only approaches to academic development but they are pervasive, hence the fear expressed in this study that educational support is often, in fact, a conduit for managerialism.

In short, the challenge to the identity of the academic comes from all quarters-from above in the form of managerial pressures to perform and measure, from below in the form of pressure from students to teach certain things in certain ways and sideways pressure from academic developers. These pressures are not necessarily negative in themselves-a concern for good-quality teaching, support from academic development, growth in scholarship of teaching, increasing student involvement in teaching, changing student needs and empowered student voice are all desirable in higher education. However, what is of interest here is the ways in which these factors are utilised and the effect that this has upon teaching staff.

\section{Academic identity and ontological insecurity}

The notion of ontological insecurity comes from R. D. Laing and describes the unreal or 'inauthentic' individual who must deny or camouflage what he or she really thinks and feels to such an extent that they no longer know what they think or feel. This is as opposed to ontological security which is the feeling of being a whole person, secure in one's own being. Ontological insecurity is enacted in life as an empty performance which is detached and disembodied:

The unreal man learned to cry when he was amused and to smile when he was sad. He frowned his approval and applauded his displeasure. All that you can see is not me. (Laing, 1965, p. 37)

Giddens (1991) argues that in response to the impact of modernisation, technology, globalisation and the disembedding of social relations from their social context, new forms of identity have emerged as a response to the ontological and existential insecurities that have been created. Giddens writes of a new age of self-absorption in which one is constantly monitoring one's thoughts and behaviour. This paper points to the ways in 
which the ontological insecurity has resulted from the need for the academic to be constantly vigilant. Changes in the nature and construction of critical thinking are emblematic of this change because critical thinking has been viewed as so central to higher education. Yet there appears to be a shift in the ways in which critical thinking is fundamental to the professional identity of the academic.

This notion of ontological insecurity is a key theme which resonates through many of the interviews and is illustrated in the extracts presented in this paper. This is voiced less as an insecurity regarding the place of the academic within his or her discipline but rather an uncertainty regarding their autonomy and expertise as teachers. There is no longer a sense of certainty about what the 'right thing' is, nor how to go about achieving it. Thus it is a vocational insecurity since this uncertainty pertains to professional practice. However, it runs deeper than this since it touches upon questions of morality and identity. Because these questions exist at a moral as well as pragmatic level they challenge both the role, but more fundamentally the identity, of the academic.

Inherent in the idea of ontological insecurity is the notion of academic identity. Academic identity is a complex idea discussed in detail by Henkel (2005), who defines it as firstly a unique individual located in a moral and intellectual framework and secondly an embedded individual with a place in institutional and community structures. Thus academic identity is both personal and professional, individual and social. Henkel (2000) argues that academic communities provide the structures, roles and social positioning. Academic identities, because they are social, are embedded in and shaped and reinforced by context and the social processes. For Henkel, identity is the interaction between individuals who are often (but not always) pursuing the same goals. Henkel (2005) identifies the discipline (often given tangible form in departments) and the institution as the key community and hence source of identification. However, there is also a further source of identity since academics identify as members of a profession with particular features including knowledge production and transfer and this professional identity crosses disciplinary and institutional boundaries. Academics see themselves as "belonging to a distinctive and bounded sector of society, the normative power of which has been sustained in part by a nexus of myths, socialisation processes and regulatory practices' (Henkel, 2005, p. I58).

This notion of a professional identity is significant since it is argued in this paper that it is an identity in flux. There is increasing formalisation and control of academia in that there is a growth in formal training for teaching as part of the induction into academic life alongside the research apprenticeship embodied in the Ph.D. In addition to this is increased external monitoring, for example of research output, decreased emphasis on basic or pure research and increased pressure for research to be strategic and to be linked with industry. Henkel (2005) identifies the two most important aspects of academic identity as academic freedom or autonomy and the centrality of the discipline. Academic freedom is defined in a variety of ways, including the ability to pursue one's own research agenda and manage the pattern of one's own working life. However these are now under threat and notions of autonomy have shifted along with increased public accountability, the requirement to respond to the needs of multiple markets and the pressures of externally defined evaluative criteria. Increasing bureaucratisation, administrative and academic scrutiny and reduced security of tenure have resulted in changes in the ways in which 
academics identify, the sources of identification and how academics locate themselves. As higher education increasingly becomes an instrument of government economic policy, this redefinition of the relationship between higher education and the state is resulting in a fracturing of the academic identity (Harris, 2005).

Morley (2003) claims that the quality agenda has produced a climate of moral panic and that the academy has become a site of social anxiety and fear and that a new defensiveness is emerging. She outlines this defensiveness in terms of the need to describe things which are in fact very complex such as teaching and research in terms of simple classifications which then become tools of evaluation of quality and performance. Thus flexibility and nuance are lost in the move towards predictability and measurability. Outcomes, teaching scores, rankings, measurement of research output and league tables can never capture complexity, promote creative daring nor engender radical critique.

\section{Critical thinking in a changing landscape}

Critical thinking has become a commodity in higher education. Commodification occurs when economic value becomes assigned to something that traditionally would not be considered in economic terms, for example an idea. A commodity is something that is exchanged for something else. Critical thinking has become a commodity because it is utilised as a product as it is included in the higher education package that is sold to students and yet at the same time that product is not closely examined. Marginson (1995) argues that knowledge produced for exchange value has become more important than that produced for use value. This commodification is part of the pressure towards serving commercial rather than human interests and part of the corporatisation of universities in which internal accountability is replaced by budgetary mechanisms of planning and control.

So what has become of critical thinking? Through the discourse of the modern university, power is, in Foucault's (1977) terms, exercised through its invisibility. Further, there is a powerful moral dimension. Reviews and appraisals are associated with notions of improvement and quality and hence cannot be challenged. Those who challenge are cast as outsiders who are not interested in good teaching, quality research or self-improvement. Notions of quality and accountability become 'taken for granted' and part of what is right and good and who we are. Gale (2000) suggests that critique becomes interpreted as an appeal to a past golden age of universities and hence old-fashioned. He suggests that arguments become positioned in binary terms as 'those for and those against vision and change' (p. 125). Academics who critique the current state of the university are characterised as ignorant of the failings of universities past. This is, he suggests, a 'strawman that market discourse creates in order for dissidents to be dispelled' (p. 125). Those who question the reliance on quality of teaching surveys are characterised as being against 'good teaching' or 'student feedback'; those who question the educational value of online teaching or reliance on PowerPoint are Luddites; those concerned about reliance on international student money are racist; and those who voice concerns about the entrepreneurial university have their heads in the sand. As Clegg comments, in the language of the new managerialism, academics who argue that the purpose of education is to develop critical thought are framed not as radicals but as conservatives (Clegg, 200I, cited in Morley, 2003). 
The notion of what an academic does, or should do, is now more contestable. The move towards a more economically driven, entrepreneurial notion of what being an academic entails has challenged the autonomy and expertise of academics and has neutralised critique. Academic identity now relies upon instrumental and economic values as well as (or in some cases instead of) educational ones. There is a loss of academic authority (Barnett, 1994) as the power of pure disciplinary knowledge is eroded and the role of academic as expert is challenged. Kogan (2005) argues that it has become possible for the state to 'know' what are the constituents of good education and research in schools and higher education and that this has been reduced to 'arithmetical epistemics' (p. 17). The changes in managerial practice with the power structure moving towards a top-down approach have occurred alongside changes in stability of employment and changes in promotion. Barnett (1999, p. 256) observes that 'what it is to be an academic is by no means given but is a matter of dynamic relationship between social and epistemological interests and structures'. Currently, the fragmentation of the academic workplace, which is in part due to changes in the managerial structure, has increased the hierarchy, increased competition and hence had a profound effect on the ways in which academics define their sense of identity (Henkel, 2005).

While the participants in this study voice concerns about the place of critique, this paper does not seek to suggest that academic staff are powerless victims. Many have utilised the changes in higher education to their advantage, while for others there are transgressive spaces both private and public. It would be overly simplistic to argue that university management has been uniformly co-opted by a managerialist agenda; some of the participants in this study held senior positions within their departments. Furthermore, many academic staff do have considerable agency within their research lives and in their teaching. The relationship between students and staff is, moreover, not a simple one in which staff no longer wield control as staff have considerable influence over the lives of students in the arena of assessment. In short, the contention of this paper is that there have been considerable and well-documented changes in higher education and that the effect of these changes is clearly voiced by the participants in this study, but that the relationships between society, government, university administration, staff and students are highly complex and in a state of flux.

\section{Conclusion}

One of the purposes of the university has been to hold a critical lens to society across the breadth of human endeavour and so one function of the university has also been to teach students to critique society, and their own role and the role of their chosen profession in that society. However, as one of the participants pointed out,

Students cannot be expected to have minds that are any more open than the minds of their teachers. Universities are not always as good as they could be at encouraging debate, challenging students to think and presenting them with different models and ways of thinking. (Medicine)

This paper has addressed the nexus between the complexities of teaching, the commodification of critique and its neutralisation through the characterisation of radical dissent as 
a reactionary stance. The role of the academic as social critic (and so by implication a critic of universities) is now contested. Furthermore, the role of the academic as a teacher of the sort of thinking that critiques, probes and exposes has become more problematic. The change in academic identity has caused a loss of certainty about the expertise and independence of the academic. If universities are moving away from critique as one of their central aspirations then this should not happen by stealth. This is a small-scale study that examined the perceptions of a limited number of academic staff. Yet through the voices of the academics interviewed it reveals a sense of profound uncertainty surrounding the role of the academic in higher education.

\section{Note}

I. Department of Education, Science and Training is the Australian Federal Government department responsible for higher education.

\section{Note on contributor}

Anna Jones is a researcher, teacher and academic developer in the Faculty of Economics and Commerce at the University of Melbourne. Her research interests include generic attributes, disciplinary culture and constructions of teaching in higher education.

\section{References}

Australian Council for Educational Research (200I) Graduate skills assessment (Canberra, Department of Education, Training and Youth Affairs).

Ball, S. (2003) The teacher's soul and the terrors of performativity, Journal of Education Policy, 18(2), 21 5-228.

Barnett, R. (1994) The limits of competence: knowledge, higher education and society (Buckingham, Society for Research into Higher Education and Open University Press).

Barnett, R. (1997) Higher education: a critical business (Buckingham, Society for Research into Higher Education and Open University Press).

Barnett, R. (1999) Realizing the university in an age of supercomplexity (Buckingham, Society for Research into Higher Education and Open University Press).

Barnett, R. (2000) University knowledge in an age of supercomplexity, Higher Education, 40, 409-422.

Barnett, R. (2003) Beyond all reason: living with ideology in the university (Buckingham, Society for Research into Higher Education and Open University Press).

Ennis, R. (1987) A taxonomy of critical thinking dispositions and abilities, in: J. Baron \& R. Sternberg (Eds) Teaching thinking skills: theory and practice (New York, Freeman).

Facione, P. A. (1990) Critical thinking: a statement of expert consensus for purposes of educational assessment and instruction. 'The Delphi Report' (Millbrae, CA, American Philosophical Association, The California Academic Press).

Facione, P. A. (1996-97) Critical thinking: what it is and why it counts. Available online at: www.calpress.com/ critical.html (accessed 16 November 2000).

Fallows, S. \& Steven, C. (Eds) (2000) Integrating key skills in higher education: employability, transferable skills and learning for life (London, Kogan Page).

Foucault, M. (1977) Discipline and punish: the birth of the prison (A. Sheridan, Trans.) (New York, Pantheon Books).

Gale, T. (2000) Putting academics in their place, Australian Educational Researcher, 27(2), |2|-|35.

Giddens, A. (1991) Modernity and self-identity: self and society in the late modern age (Cambridge, Polity). 
Goffman, E. (1956) The presentation of self in everyday life (Harmondsworth, Penguin).

Habermas, J. (197I) Knowledge and human interest (Boston, Beacon).

Halpern, D. (1996) Thought and knowledge: an introduction to critical thinking (3rd edn) (Mahwah, NJ, Lawrence Erlbaum Associates).

Harris, S. (2005) Rethinking academic identities in neo-liberal times, Teaching in Higher Education, 10(4), $42 I-433$.

Henkel, M. (2000) Academic identities and policy change in higher education (London, Jessica Kingsley Publishers).

Henkel, M. (2005) Academic identity and autonomy in a changing policy environment, Higher Education, 49(I-2), I55-176.

Jones, A. (2006) Re-disciplining generic skills: an examination of the relationship between the disciplinary context and generic skills in higher education. Unpublished Ph.D. thesis, University of Melbourne.

Jones, A. (2007) Multiplicities or manna from heaven? Critical thinking and the disciplinary context, Australian Journal of Education, 5(I), 84-103.

Kogan, M. (2005) Modes of knowledge and patterns of power, Higher Education, 49(I), 9-30.

Kurfiss, J. (1988) Critical thinking: theory, research, practice and possibilities (Washington, DC, ASHE-ERIC Higher Education Report No. 2).

Laing, R. D. (1965) The divided self: an existential study in sanity and madness (Harmondsworth, Penguin).

Land, R. (2003) Orientations to academic development, in: H. Eggins \& R. McDonald (Eds) The scholarship of academic development (Buckingham, Society for Research into Higher Education and Open University Press).

McInnis, C. (200I) Signs of disengagement? The changing undergraduate experience in Australian universities (Melbourne, University of Melbourne, Centre for the Study of Higher Education).

McPeck, J. (198I) Critical thinking and education (New York, St Martin's).

McPeck, J. (1990) Teaching critical thinking: dialogue and dialectic (New York, Routledge).

McWilliam, E. (2002) Against professional development, Educational Philosophy and Theory, 34(3), 289-299.

Marginson, S. (1995) Markets in higher education: Australia, in: J. Smyth (Ed.) Academic work (Buckingham, Open University Press).

Morley, L. (2003) Quality and power in higher education (Philadelphia, PA, Society for Research into Higher Education and Open University Press).

Paul, R. (1989) Critical thinking in North America: a new theory of knowledge, learning and literacy, Argumentation, 3, 197-235.

Pennycook, A. (200I) Critical applied linguistics: a critical introduction (Mahwah, NJ, Lawrence Erlbaum).

Ramsden, P. (1992) Learning to teach in higher education (London, Kogan Page).

Shulman, L. S. (1993) Teaching as community property; putting an end to pedagogical solitude, Change, 25(6), 6-7.

Siegel, H. (1988) Educating reason: rationality, critical thinking and education (New York, Routledge).

van der Wal, A. (1999) Critical thinking as a core skill: issues and discussion paper, paper presented at the Higher Education Research and Development Society of Australasia Annual International Conference, Melbourne, July. 